\title{
A Pacific Islander Organization’s Approach Towards Increasing Community Colorectal Cancer Knowledge and Beliefs
}

\author{
Roger Sur ${ }^{1}$, Ruth Peters ${ }^{1}$, Leah Leilani Beck ${ }^{2}$, Melevesi Fifita ${ }^{3}$, Maria Gonzalez ${ }^{2}$, Linda \\ Guevara $^{4}$, Paula Healani Palmer ${ }^{5}$, and Sora Park Tanjasiri ${ }^{1}$ \\ ${ }^{1}$ California State University Fullerton \\ ${ }^{2}$ St. Joseph Hospital of Orange \\ ${ }^{3}$ Pacific Islander Health Partnership \\ ${ }^{4}$ Guam Communications Network \\ ${ }^{5}$ Claremont Graduate University
}

\begin{abstract}
Purpose: Evaluate the educational intervention and determine if changes in knowledge and beliefs are associated with positive intentions to screen among Pacific Islanders (PIs). Design: Pre- and post-test surveys were utilized to evaluate the intervention. Educational materials included an in-language presentation, educational videos, and bookmarks with screening re-enforcement messages for communitybased PI groups. Methods: One hundred and ninety-six PIs aged 50 years and older residing in Orange County completed the educational workshop. The dependent variable is intention and the independent variables are demographic, enabling, and predisposing characteristics. Statistical analyses included paired samples t-tests, chi-square tests, and two logistic regression models. Results: Knowledge and belief scores increased pre- to post-test. A majority intended to (1) talk to a doctor about colorectal cancer (CRC) screening (74.5\%), and (2) participate in CRC screening (73.5\%). Positive change in knowledge score was a significant predictor for intending to talk to a doctor about CRC screening; female gender and positive change in knowledge score were significant predictors for intending to participate in screening. Conclusion: The study highlighted the effectiveness of tailored education in addressing cultural and linguistic needs of the community. Moreover, it demonstrated the education's potential for moving participants with limited CRC screening knowledge to intend to screen.
\end{abstract}

(C) 2013 Californian Journal of Health Promotion. All rights reserved.

Keywords: community-based participatory research, Pacific Islander, colorectal cancer, knowledge, beliefs and intentions, cancer education

\section{Introduction}

California is home to the largest Chamorro population in the United States. In 2010 there were an estimated 38,199 Chamorros residing in California: $21.6 \%$ spoke a language other than English at home, $12.1 \%$ had incomes below the poverty level, $11.5 \%$ with no health insurance, $4.7 \%$ were foreign born, and $12.2 \%$ had less than a high school degree (U.S. Census Bureau, 2010).

Cancer is the second leading cause of death and a major public health concern in the United
States. Of cancers affecting both men and women, colorectal cancer (CRC) is the second leading cause of cancer incidence and mortality in the United States (44.4 per 100,000 and 16.3 respectively; U.S. Cancer Statistics Working Group, 2012). Pacific Islanders experience relatively higher rates of cancer incidence and mortality compared to other racial/ethnic groups. Recent data from Miller, Chu, Hankey, and Ries (2008) using Surveillance, Epidemiology, and End Results registries from 1998 to 2002 reported cancer incidence and mortality for disaggregated Pacific Islander groups. For instance, they reported CRC incidence rates for 
Native Hawaiian (44.0 per 100,000; 95\% CI: 37.3, 51.6) and Samoan women (38.6 per 100,000; 95\% CI: 24.1, 60.5), and CRC mortality rates for Native Hawaiian women (13.1 per 100,000; 95\% CI: 9.5, 17.7). These rates underscore the importance of screening and early detection to address CRC health disparities.

\section{Colorectal Screening}

Regular CRC screening should begin at age 50 and continue until age 75; screening procedures include sigmoidoscopy, colonoscopy, and fecal occult blood testing (FOBT; U.S. Preventive Services Task Force, 2008). According to the Centers for Disease Control and Prevention (n.d.), the removal of precancerous polyps can prevent the onset of CRC. Unfortunately, many Pacific Islanders underutilize CRC screening; they have one of the lowest screening rates compared to other racial/ethnic groups (Lee, Lundquist, Ju, Luo, \& Townsend, 2011). In 2008, 39\% of Native Hawaiian and Pacific Islander adults 50 years and older did not receive a blood stool test in the past two years (Agency for Healthcare Research and Quality, 2010).

\section{Knowledge, Attitudes, and Beliefs Regarding Cancer Screening}

Studies have shown that knowledge, attitudes and beliefs (KABs) can facilitate or impede healthcare access and contribute to cancer screening disparities. For instance, findings by James, Daley, and Greiner (2011) indicated that low CRC knowledge and negative screening beliefs were associated with lower CRC screening among African American men. Moreover, KABs of cancer screening vary among communities and subgroups. Although studies specific to Pacific Islanders are limited, Dang, Lee, and Tran (2010) found differences in KABs among four disaggregated Asian American and Pacific Islander groups of women in California. These findings suggest that knowledge and beliefs can act as a barrier to healthcare access, and that there are variations in KABs specific to subpopulations. Such findings suggest the development of specific interventions aimed at increasing cancer screening knowledge and beliefs to address cancer health disparities.

Colorectal Screening Interventions among Chamorros and Other Pacific Islanders

Southern California is home to an estimated 17,885 Chamorros (U.S. Census Bureau, 2000). Relatively little is known about Chamorro CRC incidence, mortality, and screening rates as well as KABs among Chamorros and other Pacific Islanders. Nevertheless, studies have shown culturally tailored interventions targeting KABs were effective at modifying screening and other health behaviors. For instance, tailoring an intervention and making it culturally and linguistically appropriate to Chamorros has been effective in educating and modifying breast cancer screening behavior (Manglona et al., 2010). Further, Gotay et al. (2000) found that a culturally tailored cancer education intervention increased breast and cervical cancer screening among Native Hawaiian women. Cultural tailoring facilitates the overcoming of language and culture barriers, as well as addresses social norms regarding the discussion of certain body parts and health. A culturally tailored CRC educational intervention would aim to improve screening behaviors by increasing knowledge and positive beliefs of CRC and screening. Therefore, the purpose of this paper is to assess the impacts of the culturally tailored educational intervention on changes in knowledge and beliefs regarding CRC and screening among Chamorros and other Pacific Islanders. Furthermore, we sought to determine if changes in knowledge and beliefs are associated with positive intentions to talk with a doctor about CRC screening and positive intentions to participate in screening among Chamorros and other Pacific Islanders 50 years and older. The Guam Communications Network (GCN) and Pacific Islander Health Partnership (PIHP) organizations along with St. Joseph Hospital of Orange conducted this study, however, a majority of participants were educated by GCN.

\section{Methods}

\section{Study Design}

This is a one-group, pre-test/post-test evaluation of CRC education workshops for Chamorro and 
other Pacific Islander adults in Orange County. Educational workshops were conducted over a one and a half year period by Pacific Islander community health educators (CHEs). The preand post-tests were collected from participants during the education session. The purpose of the educational intervention was to increase knowledge and beliefs regarding CRC and to promote screening among Chamorros and other Pacific Islanders. The objective was to facilitate positive intentions to get screened, and the goal was to increase screening behavior. By analyzing pre- and post-test surveys we assessed the impact of the educational workshop on increasing knowledge and beliefs, and explored the relationship between changes in knowledge and beliefs with intentions to get screened. Therefore, the main variables of interest were changes in knowledge and beliefs of CRC and screening, and intentions to talk to a doctor about screening and to participate in screening. It should be noted that attitudes regarding CRC were not measured and therefore not part of the analyses. This study was made possible by a community collaborative called WINCART (Weaving and Islander Network for Cancer Awareness, Research and Training). Through WINCART, GCN and PIHP partnered with St. Joseph Hospital of Orange to provide CRC education and services to the Pacific Islander communities of Orange County.

\section{Participants}

The CRC educational workshop targeted Chamorro, Samoan, Marshallese, Native Hawaiian, and Tongan men and women ages 18 to 70 years and older who reside in Orange County. While the intent was to recruit from all Native Hawaiian and other Pacific Islander populations, the sample is predominantly Chamorro females. In total there were 239 participants educated; however, 196 were included in the analyses because the target age group for CRC screening was 50 years and older. Participants were recruited from community-based organizations, churches, and other health workshops (i.e., diabetes, heart 101, breast cancer). Educational workshops were held at churches, community centers, one-on-one meetings, community clinics, community-based organizations, and participant's homes. The workshops that took place through one-on-one meetings and at participant's homes were due to travel challenges.

\section{Culturally Tailored Education Materials}

Kreuter's framework for achieving cultural appropriateness was utilized in developing the flipchart, bookmark, handout and videos (Kreuter, Lukwago, Bucholtz, Clark, \& SandersThompson, 2003). This involved the inclusion of Pacific Islander images of cultural items (i.e., tapa cloths, palm trees and pandanus weaved mats), sociocultural cues (i.e., reference to religion, faith, and ethnic pride), relevant statistics regarding cancer incidence and mortality rates, and appropriate written language translation of bookmark, handout and flipchart into Chamorro, Marshallese, Samoan, and Tongan languages. These in-language materials were first drafted in English, tested for readability using a Simple Measure Of Gobbledygook (SMOG) grading (McLaughlin, 1969), and then translated by bilingual community partners. The SMOG grade formula was developed by Harry McLaughlin and is used to assess the readability of health messages. Both the CHE and the education materials (flip chart, handout and bookmark) reflected the language that the participant felt most comfortable using.

\section{Educational Workshop and Data Collection}

CHEs distributed and collected selfadministered surveys during the educational workshop. Participants signed-in as they entered the workshop. After signing in, the pre-test and post-test were distributed simultaneously; both tests were coded to ensure that the pre-test match with the post-test. Participants completed the pre-test then were shown a culturally tailored 60 -second video that briefly introduces CRC and shows Pacific Islander cancer survivors emphasizing the importance of screening. Afterwards, a 60-minute CRC educational flipchart presentation was shown. At the conclusion of the presentation, participants were shown a four-minute culturally tailored video that emphasizes the importance of an individual's health to their family and community. This video also featured cancer survivors and community leaders further emphasizing the 
importance early detection, and encouraged individuals to speak to a doctor to learn more about CRC screening. In addition, CHEs distributed informational handouts, bookmarks with screening reinforcement messages, and a resource list of FOBT sites. At the end of the workshop participants completed the post-test. For bilingual and non-English speaking participants, depending upon their language (Chamorro, Marshallese, Samoan, and Tongan), appropriately translated in-language pre-and post-tests were distributed, and the CHEs assisted with further translating and competing the survey.

Thank you gifts were given to participants for completing the surveys. Informed consent was obtained from participants implicitly when they chose to complete the pre-test and post-test survey. The data was collected and entered into SPSS (version 19) for analyses. All data collection instruments and procedures were approved by the California State University Fullerton Institutional Review Board.

\section{Measures}

Demographic, enabling, predisposing, and intention variables were adapted from the California Health Interview Survey (CHIS, 2001). The demographic variables were: age, gender, educational attainment, race/ethnicity, and birthplace. The enabling variables were: received a referral for cancer screening, number of times seeing a doctor in the past 12 months, and ever heard of a sigmoidoscopy, colonoscopy, or FOBT. The predisposing variables were knowledge and beliefs of CRC and screening. There were six knowledge variables: two regarding knowledge of CRC (e.g. having a family history of colorectal cancer increases your chance of developing the disease), and four on CRC screening (e.g. colorectal cancer screening should start at which age?). In addition, there were nine belief variables: five regarding beliefs of CRC (e.g. colorectal cancer is not a problem for Pacific Islanders), and four on CRC screening (e.g. I am afraid/concerned that some colorectal cancer screening procedures are painful). Knowledge and belief variables were dichotomous with " 0 " indicating incorrect or negative beliefs, and " 1 "
Table 1

\begin{tabular}{|c|c|c|}
\hline \multicolumn{3}{|c|}{ Demographic Characteristics $(n=196)$} \\
\hline Characteristic & $\mathrm{n}$ & $\%$ \\
\hline \multicolumn{3}{|l|}{ Age } \\
\hline $50-59$ & 90 & 45.9 \\
\hline $60-69$ & 91 & 46.4 \\
\hline 70 and older & 15 & 7.7 \\
\hline \multicolumn{3}{|l|}{ Education } \\
\hline Less than high school & 11 & 5.6 \\
\hline High school & 112 & 57.4 \\
\hline Vocational, business, or trade school & 10 & 5.1 \\
\hline Some college & 62 & 31.8 \\
\hline \multicolumn{3}{|l|}{ Gender } \\
\hline Female & 178 & 90.8 \\
\hline Male & 18 & 9.2 \\
\hline \multicolumn{3}{|l|}{ Race/Ethnicity } \\
\hline Chamorro & 179 & 91.3 \\
\hline Samoan & 8 & 4.1 \\
\hline Tongan & 6 & 3.1 \\
\hline Other Pacific Islander & 3 & 1.5 \\
\hline \multicolumn{3}{|l|}{$\begin{array}{l}\text { Have you received a referral for cancer } \\
\text { screening? }\end{array}$} \\
\hline Yes & 21 & 11.2 \\
\hline No & 167 & 88.8 \\
\hline \multicolumn{3}{|l|}{ Where were you born? } \\
\hline United States & 8 & 4.1 \\
\hline Outside of United States & 188 & 95.9 \\
\hline \multicolumn{3}{|l|}{$\begin{array}{l}\text { Have you ever heard of a Sigmoidoscopy, } \\
\text { Colonoscopy, or FOBT? }\end{array}$} \\
\hline Yes & 166 & 86.0 \\
\hline \multirow[t]{2}{*}{ No } & 27 & 14.0 \\
\hline & M & SD \\
\hline \multirow[t]{2}{*}{$\begin{array}{l}\text { During the past } 12 \text { months, how many } \\
\text { times have you seen a doctor? }\end{array}$} & 3.18 & 1.84 \\
\hline & $\mathrm{n}$ & $\%$ \\
\hline \multicolumn{3}{|l|}{ Pre-test to post-test } \\
\hline Positive change in knowledge score & 139 & 70.9 \\
\hline Positive change in belief score & 184 & 93.9 \\
\hline \multicolumn{3}{|l|}{ Post-test } \\
\hline $\begin{array}{l}\text { Plan to talk to a doctor about CRC } \\
\text { screening }\end{array}$ & 140 & 74.5 \\
\hline Plan to participate in CRC screening & 139 & 73.5 \\
\hline
\end{tabular}

indicating correct or positive beliefs. Missing responses of individual knowledge and belief 
items were assumed to indicate an incorrect response or negative belief, and were imputed as " 0 ." The number of correct answers were summed together to create a knowledge score and belief score. Lastly, there were two intention variables: intention to talk to a doctor about CRC screening, and intention to participate in CRC screening. Attitude was not measured and therefore not included in the analysis.

Table 2

Differences in Knowledge and Belief Scores, Pre-test to Post-test

\begin{tabular}{lrrrr}
\hline & Pre-test & \multicolumn{1}{c}{ Post-test } & & \\
\cline { 2 - 3 } & $\mathrm{M}(\mathrm{SD})$ & $\mathrm{M}(\mathrm{SD})$ & $\mathrm{t}$ & p-value \\
\hline Total & 3.25 & 5.78 & - & .000 \\
knowledge & $(2.05)$ & $(0.82)$ & 16.36 & \\
score & & & & \\
Total belief & 3.55 & 7.31 & - & .000 \\
score & $(2.39)$ & $(1.52)$ & 21.85 & \\
\hline
\end{tabular}

\section{Statistical Analyses}

Descriptive statistics. Frequencies and percentages were calculated to describe: age; educational attainment; gender; race/ethnicity; birthplace; received a referral for cancer screening; ever heard of a sigmoidoscopy, colonoscopy, or FOBT; positive changes in knowledge and belief scores; and positive intentions. In addition, frequencies and percentages were calculated to describe positive change in knowledge and belief scores from pretest to post-test; and plans to talk to a doctor about CRC screening, and plan to participate in CRC screening at post-test. Mean and standard deviation were calculated to describe the number of times seeing a doctor in the past 12 months.

Relational statistics. Paired samples $t$-tests were conducted to determine if there were significant differences between pre- and posttests on knowledge and belief scores. In addition, chi-square tests were conducted to assess the relationships between the independent (demographic, enabling, and predisposing characteristics) and dependent (intentions) variables measured at post-test. Lastly, two logistic regression models were conducted to assess significant predictors of intention to talk to doctor, and intention to participate in screening. Variables found to be significantly associated with intentions were included in the logistic regression model.

\section{Results}

Table 1 presents the characteristics of the participants. A majority of participants had not received a referral for cancer screening (88.8\%), were female (90.8\%), and Chamorro (91.3\%).

Evaluation found the culturally tailored education workshop resulted in $70.9 \%$ of participants with a positive increase in knowledge scores and $93.9 \%$ with a positive increase in belief scores. Post-test surveys indicated a large majority (74.5\%) intended to talk to a doctor about CRC screening, and intended to participate in CRC screening (73.5\%). Table 2 presents the paired samples ttests calculated for the total knowledge and belief score variables; it was found that the posttest total knowledge scores $(M=5.78 S D=$ 0.82 ) were significantly higher than the pre-test scores $(M=3.25 S D=2.05)$. Similarly, the posttest total belief scores $(M=7.31 S D=1.52)$ were significantly higher than the pre-test scores $(M=3.55 S D=2.39$; data not shown in table $)$.

Table 3 presents the comparisons of the independent variables to the intention variables at post-test. It was found that birthplace outside of the U.S. $(p=.001)$ and a positive change in knowledge score $(\mathrm{p}<$.001) were significantly associated with intention to talk to a doctor about CRC screening. In addition, it was found that birthplace outside of the U.S. $(p=.001)$, female $(p=.044)$, ever received a referral $(p=$ .021 ), and positive change in knowledge score $(p<.001)$ were significantly associated with intention to participate in CRC screening.

Table 4 presents the two logistic regression models exploring the relationship between the independent variables found to be bivariately associated with intentions to talk to a doctor about CRC screening, and participate in CRC screening. Positive change in knowledge score ( $\mathrm{p}<.001)$ was a significant predictor for planning to talk to a doctor about CRC screening. Female gender $(p=.001)$ and positive change in knowledge score $(\mathrm{p}<.001)$ were significant predictors for planning to participate in screening.

\section{Discussion}


Sur, R., Beck, L.L., Fifita, M., Gonzalez, M., Guevara, L., Palmer, P.H., Tanjasiri, S.P. / Californian Journal of Health Promotion 2013, Volume 11, Issue 2, 12-20

Table 3

Characteristics of Sample by Intentions at Post-test

\begin{tabular}{|c|c|c|c|c|}
\hline \multirow[b]{2}{*}{ Demographic Characteristics } & \multicolumn{2}{|c|}{$\begin{array}{l}\text { Plan to talk to doctor } \\
\text { about CRC screening }\end{array}$} & \multicolumn{2}{|c|}{$\begin{array}{l}\text { Plan to participate in } \\
\text { CRC screening }\end{array}$} \\
\hline & $\mathrm{n}(\%)$ & $\begin{array}{c}\mathrm{p}^{-} \\
\text {value }\end{array}$ & $\mathrm{n}(\%)$ & $\begin{array}{c}\mathrm{p}^{-} \\
\text {value }\end{array}$ \\
\hline Age & & 0.077 & & 0.115 \\
\hline 50-59 & $64(45.7 \%)$ & & $66(47.5 \%)$ & \\
\hline $60-69$ & $69(49.3 \%)$ & & $66(47.5 \%)$ & \\
\hline 70 and older & $7(5.0 \%)$ & & $7(5.0 \%)$ & \\
\hline Education & & 0.287 & & 0.091 \\
\hline Less than high school & 7 (5.0\%) & & 7 (5.0\%) & \\
\hline High school & $77(55.0 \%)$ & & $74(53.2 \%)$ & \\
\hline Vocational, business, or trade & $8(5.7 \%)$ & & $9(7.4 \%)$ & \\
\hline school & & & & \\
\hline Some college & $48(34.3 \%)$ & & 49 (35.3\%) & \\
\hline Gender & & 0.700 & & 0.044 \\
\hline Female & $128(91.4 \%)$ & & $130(93.5 \%)$ & \\
\hline Male & $12(8.6 \%)$ & & $9(6.5 \%)$ & \\
\hline Race/Ethnicity & & 0.111 & & 0.100 \\
\hline Chamorro & $128(91.4 \%)$ & & 127 (91.4\%) & \\
\hline Samoan & $7(5.0 \%)$ & & $7(5.0 \%)$ & \\
\hline Tongan & $5(3.6 \%)$ & & $5(3.6 \%)$ & \\
\hline Birthplace & & 0.001 & & 0.001 \\
\hline United States & $2(1.4 \%)$ & & $2(1.4 \%)$ & \\
\hline Outside of United States & $138(98.6 \%)$ & & 137 (98.6\%) & \\
\hline \multicolumn{5}{|l|}{ Enabling } \\
\hline Received a referral & & 0.062 & & 0.021 \\
\hline Yes & $10(7.5 \%)$ & & $9(6.8 \%)$ & \\
\hline No & $123(92.5 \%)$ & & $123(93.2 \%)$ & \\
\hline $\begin{array}{l}\text { Ever heard of a Sigmoidoscopy, } \\
\text { Colonoscopy, or FOBT? }\end{array}$ & & 0.861 & & 0.954 \\
\hline Yes & $121(86.4 \%)$ & & $120(86.3 \%)$ & \\
\hline No & $19(13.6 \%)$ & & 19 (13.7\%) & \\
\hline \multicolumn{5}{|l|}{ Predisposing } \\
\hline Change in knowledge scores & & 0.000 & & 0.000 \\
\hline Negative or No change & $24(17.1 \%)$ & & $22(15.8 \%)$ & \\
\hline Positive change & $116(82.9 \%)$ & & $117(84.2 \%)$ & \\
\hline Change in belief scores & & 0.309 & & 0.632 \\
\hline Negative or No change & $8(5.7 \%)$ & & $6(4.3 \%)$ & \\
\hline Positive change & $132(94.3 \%)$ & & $133(95.7 \%)$ & \\
\hline
\end{tabular}

Performed chi-square tests to determine p-values.

The study highlighted the effectiveness of tailored education in addressing cultural and linguistic needs, and increasing knowledge of CRC screening among Chamorros and other Pacific Islanders in Orange County. Our results indicate that knowledge was a significant predictor for intention to talk to a doctor. In addition, female gender and knowledge were predictors for intention to participate in screening.

The results demonstrated the education's potential at moving participants with limited
CRC screening knowledge to participate in screening. The relationship between positive change in knowledge and screening intention is consistent with other racial/ethnic minority studies that found cancer screening knowledge to be associated with screening behavior (James, Daley, \& Greiner, 2011; Sadler et al., 2007). For instance, Wang, Schwartz, Luta, Maxwell, and Mandelblatt (2012) found that an educational video improved breast cancer screening knowledge and intentions among Chinese immigrant women. Furthermore, our results suggest that increasing knowledge of screening 
Table 4

\begin{tabular}{|c|c|c|c|c|}
\hline \multicolumn{5}{|c|}{$\begin{array}{c}\text { Logistic regression model on post-test intentions related to } \\
\text { significant independent variables }\end{array}$} \\
\hline & \multicolumn{2}{|c|}{$\begin{array}{l}\text { Plan to talk to } \\
\text { doctor about CRC } \\
\text { screening }\end{array}$} & \multicolumn{2}{|c|}{$\begin{array}{l}\text { Plan to participate } \\
\text { in CRC screening }\end{array}$} \\
\hline & $B$ & p-value & $B$ & p-value \\
\hline Gender & -- & -- & -2.51 & .001 \\
\hline $\begin{array}{l}\text { Birthplace } \\
\quad \text { Outside United States }\end{array}$ & 21.05 & 0.998 & 22.94 & 0.998 \\
\hline Received a referral & -- & -- & -- & -- \\
\hline $\begin{array}{l}\text { Change in knowledge } \\
\text { scores }\end{array}$ & 2.11 & .000 & 2.49 & .000 \\
\hline
\end{tabular}

can lead to future intentions in CRC screening. These findings underscore the importance of understanding and addressing knowledge and beliefs that Chamorros and other Pacific Islanders have concerning CRC screening. Future research should focus on whether intentions lead to actual receipt of CRC screening.

\section{Limitations}

There are some limitations to this study that should be considered. First, there was no control group for this study and the data obtained is selfreported and the study is based on a nonprobability, community-based sample. Furthermore, findings may not be generalized to men and to non-Chamorro Pacific Islanders outside of Orange County. This study, however, is unique and contributes to the literature for future educational interventions targeting screening behaviors in Chamorro and other Pacific Islanders.

\section{Conclusion}

This study provides preliminary evidence that the cultural appropriateness of the recruitment, education and overall intervention contributed largely to its success. It allowed the CHEs to gain access to the communities and to gain a trusting, working relationship among community members. Moreover, within the Pacific Islander culture there are norms and taboos with regards to speaking about health and the body. Therefore, the cultural appropriateness of the intervention addressed these cultural and linguistic barriers, thereby allowing greater access to the community, and greater understanding within the community.

\section{Acknowledgements}

The authors thank the following people for their contribution to this project: Greta Briand, Keith Castro, Dorothy Vaivao, staff from Guam Communications Network, staff from Pacific Islander Health Partnership, and staff from St. Joseph Hospital of Orange. This project was supported by grant number 1U54CA153458 from the National Cancer Institute, Center to Reduce Cancer Health Disparities (NCI CRCHD) and grant number 10AT1093 from SAIC-Frederick, Inc. The contents are solely the responsibility of the authors and do not necessarily represent the official views of the NCI CRCHD or SAIC-Frederick, Inc.

\section{References}

Agency for Healthcare Research and Quality. (2010). National Healthcare Disparities Report, 2009. Rockville, MD: U.S. Department of Health and Human Services, Agency for Healthcare Research and Quality.

Centers for Disease Control and Prevention (CDC). (n.d.). Colorectal (colon) cancer. Retrieved from http://www.cdc.gov/cancer/colorectal/basic_info/index.htm 
Sur, R., Beck, L.L., Fifita, M., Gonzalez, M., Guevara, L., Palmer, P.H., Tanjasiri, S.P. / Californian Journal of Health Promotion 2013, Volume 11, Issue 2, 12-20

Dang, J., Lee, J., \& Tran, J. H. (2010). Knowledge, attitudes, and beliefs regarding breast and cervical cancer screening among Cambodian, Laotian, Thai, and Tongan women. Journal of Cancer Education, 25, 595-601.

Gotay, C. C., Banner, R. O., Matsunaga, D. S., Hedlund, N., Enos, R., Issell, B. F., \& DeCambra, H. (2000). Impact of a culturally appropriate intervention on breast and cervical screening among Native Hawaiian women. Preventive Medicine, 31, 529-537.

James, A. S., Daley, C. M., \& Greiner, K. A. (2011). Knowledge and attitudes about colon cancer screening among African Americans. American Journal of Health Behavior, 35(4), 393-401.

Kreuter, M. W., Lukwago, S. N., Bucholtz, D. C., Clark, E. M., \& Sanders-Thompson, V. (2003). Achieving cultural appropriateness in health promotion programs: Targeted and tailored approaches. Health Education Behavior, 30(2), 133-146.

Lee, H. Y., Lundquist, M., Ju, E., Luo, X., \& Townsend, A. (2011). Colorectal cancer screening disparities in Asian Americans and Pacific Islanders: Which groups are most vulnerable? Ethnicity \& Health, 16(6), 501-518.

Manglona, R. D., Robert, S., Isaacson, L. S. N., Garrido, M., Henrich, F. B., Santos, L. S., Peters, R. (2010). Promoting breast cancer screening through storytelling by Chamorro cancer survivors. Californian Journal of Health Promotion, 8, 90-95.

McLaughlin, G. (1969). SMOG grading: A new readability formula. Journal of Reading, 12(8), 639-646.

Miller, B. A., Chu, K. C., Hankey, B. F., \& Ries, L. A. G. (2008). Cancer incidence and mortality patters among specific Asian and Pacific Islander populations in the U.S. Cancer Causes Control, 19, 227-256.

Sadler, G. R., Ko, C. M., Cohn, J. A., White, M., Weldon, R., \& Wu, P. (2007). Breast cancer knowledge, attitudes, and screening behaviors among African American women: the Black cosmetologists promoting health program. BMC Public Health, 7(57), 1-8.

UCLA. (2001). California Health Interview Survey. UCLA Center for Health Policy Research.

U.S. Cancer Statistics Working Group. (2012). United States Cancer Statistics: 1999-2008 Incidence and Mortality Web-based Report. U.S. Department of Health and Human Services, Centers for Disease Control and Prevention and National Cancer Institute. Atlanta, GA. Retrieved from www.cdc.gov/uscs

U.S. Census Bureau. (2000). American FactFinder. Washington, DC: Author. Retrieved from http://www.factfinder2.census.gov

U.S. Census Bureau. (2010). 2010 American Community Survey. Washington, DC: Author. Retrieved from http://www.factfinder2.census.gov

U.S. Department of Health and Human Services. (2011). Health, United States, 2010. Hyattsville, MD: National Center for Health Statistics.

U.S. Preventive Services Task Force. (2008). Screening for Colorectal Cancer: U.S. Preventive Services Task Force Recommendation Statement. AHRQ Publication 08-05124-EF-3, October 2008. Retrieved from http://www.uspreventiveservicestaskforce.org/uspstf08/colocancer/colors.htm

Wang, J. H., Schwartz, M. D., Luta, G., Maxwell, A. E., and Mandelblatt, J. S. (2012). Intervention tailoring for Chinese American women: Comparing the effects of two videos on knowledge, attitudes and intentions to obtain a mammogram. Health Education Research, 27(3), 523-536. 
Sur, R., Beck, L.L., Fifita, M., Gonzalez, M., Guevara, L., Palmer, P.H., Tanjasiri, S.P. / Californian Journal of Health Promotion

Author Information

*Roger Sur, MPH

California State University Fullerton

Department of Health Science

800 N. State College Blvd.

KHS 115

Fullerton, CA 92831

Email: rosur@fullerton.edu

Phone: 657-278-3197

Ruth Peters, MPH

California State University Fullerton

Department of Health Science

Leah Leilani Beck

St. Joseph Hospital of Orange

Center for Cancer Prevention and Treatment

Melevesi Fifita

Pacific Islander Health Partnership

Maria Gonzalez

St. Joseph Hospital of Orange

Center for Cancer Prevention and Treatment

Linda Guevara

Guam Communications Network

Paula Healani Palmer, PhD

Claremont Graduate University

Community and Global Health

Sora Park Tanjasiri, DrPH

California State University Fullerton

Department of Health Science

* corresponding author 